TP Periodica Polytechnica Civil Engineering

62(4), pp. 1052-1059, 2018

https://doi.org/10.3311/PPci.13005

Creative Commons Attribution (i)

RESEARCH ARTICLE

\section{Analysis and Finite Element Modelling of Water Flow in Concrete}

\author{
Miklós Pap ${ }^{1 *}$, András Mahler ${ }^{1}$, Salem Georges Nehme ${ }^{2}$
}

Received 16 August 2018; Revised 12 September 2018; Accepted 14 September 2018

\begin{abstract}
Due to the construction of underground structures and hazardous waste storages, understanding and modelling of seepage in concrete has become an important issue in life-span analyses. The theories and calculation methods of unsaturated soil mechanics provide an opportunity to analyze water flow in other types of porous media (e.g. concrete) as well. This study deals with the determination of the permeability for unsaturated and saturated concrete and modelling the water flow in concrete. The direct measurement of the saturated permeability, the preparation of the drying water retention curve and determination of the depth of penetration of water under pressure are involved in the series of tests. For the fitting method of the experimental water retention curves were used Fredlund and Xing (1994) and van Genuchten (1980) model. The theory of lateral shift was applied to estimate the wetting water retention curve from the drying WRC. Thus, we could calculate the unsaturated permeability functions with Fredlund et al. (1994) and van Genuchten (1980) model. The finite element modelling of the standard test for watertightness were performed with Midas GTS using the measured and calculated unsaturated property functions.
\end{abstract}

\section{Keywords}

concrete, permeability coefficient, water retention curve, standard test for watertightness, finite element modelling

\section{Introduction}

In geotechnical engineering it is a frequent task to analyze and model seepage in soils. The theories of unsaturated soil mechanics can be applied to calculate and examine the water flow in other unsaturated porous material such as concrete too. The aim of the work presented is to examine whether definitions, concepts, theories and calculation methods used in geotechnical engineering could be applicable to model seepage in concrete too.

For saturated soils, the pore water pressure $\left(u_{w}\right)$ and total stress $(\sigma)$ are the initial values for determining the state variables. In this case, the role of $u_{w}$ is generally negligible since the compressibility of the water is small and the shear strength of water is zero, so the application of two independent stress state variables $\left(\sigma-u_{w}, u_{w}\right)$ is accepted, thus the stress state of the saturated soil is the effective stress. [2]

For unsaturated soils, there are three different measurable stress variables: the total stress, the pore air pressure $\left(u_{a}\right)$ and the pore water pressure $\left(u_{w}\right)$. In formulating unsaturated soil mechanical problems, the $\sigma-u_{a}, u_{a}-$ uw combination gained the widest acceptance, where $\left(\sigma-u_{a}\right)$ is the net normal stress and $\left(u_{a}-u_{w}\right)$ is the matric suction. These seems to be the two most appropriate stress state variables for describing the unsaturated soils behavior. [2]

The soil-water retention curve (SWRC) which defines the relationship between suction and a certain measure of water content (i.e. degree of saturation, gravimetric or volumetric water content), has an important role in the determination of unsaturated soil property functions. The procedures that have been proposed for unsaturated soil properties are approximate but are generally satisfactory for analyzing problems related to unsaturated soil mechanics [2]. Many studies have been published that the water content has a large effect on the mechanical properties of concrete and rock as well [14-16].

The typical water retention curve can be divided into three distinct zones (Fig. 1). The first part where the suction value is lower than the air entry value and the soil is quasi saturated. The curve in this zone is almost horizontal. When suction increases beyond the air entry value the water content drops 


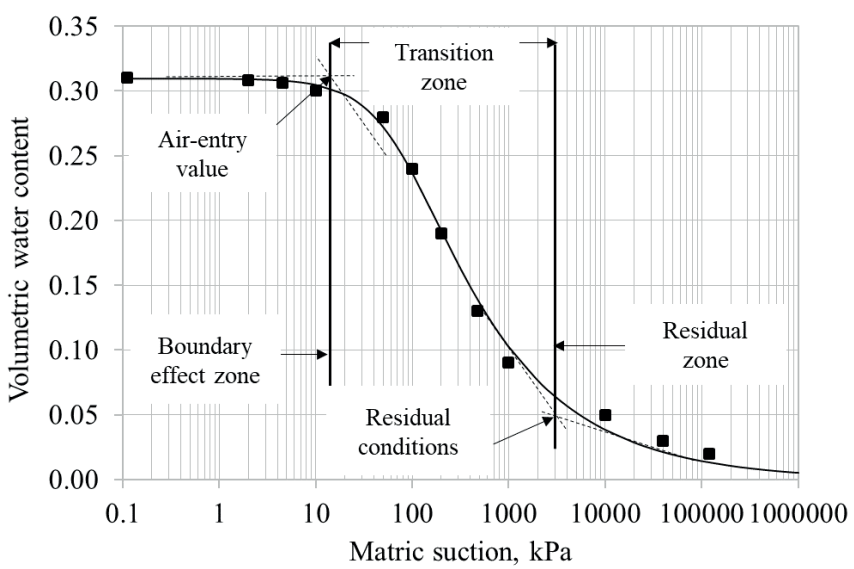

Fig. 1 The three distinct zones of water retention curve after Fredlund et al. 2011 [3]

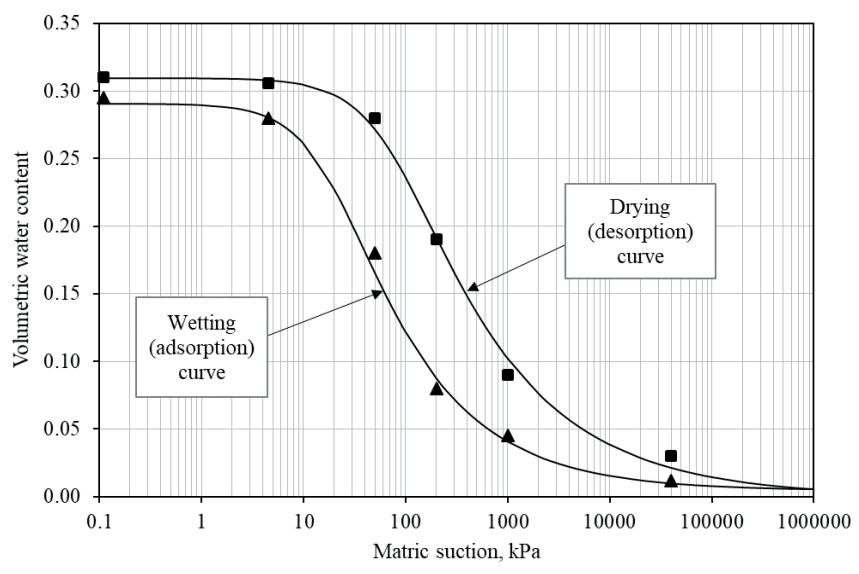

Fig. 2 The hysteresis loops of a water retention curve after Fredlund 2000 [4]

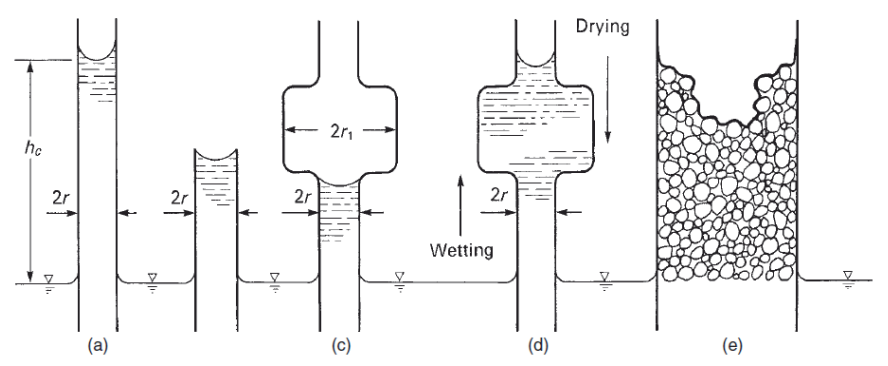

Fig. 3 Height, radius, and shape effects on capillarity after Taylor 1948 [10]

significantly, and the air content is increasing in the same time. This part is called transition zone. In the last segment the decrease in water content is lower, because the water phase is not continuous anymore in the soil. This part is called residual zone. The shape of the water retention curve depends primarily on the pore size distribution of soils, which has a strong correlation to grain size distribution $[3,8]$.

The water retention curves are different during wetting (adsorption) and drying (desorption) process (Fig. 2), because non-uniform pore size distribution in a soil results in hysteresis in the soil-water retention curve. This phenomenon is frequently illustrated by the capillary tube analogy. The water contents during the wetting and drying processes are different at particular matric suction values, as illustrated by the examples shown in Fig. 3, respectively. The contact angle at an advancing interface during the wetting process is also different from that at a receding interface during the drying process. The above factors as well as the presence of entrapped air in the soil are considered to be the main causes for hysteresis in the drying and wetting soil-water retention curves. [2, 10]

\section{Materials and methods}

\subsection{Concrete mixtures and specimens}

In order to investigate the water retention curves of concrete materials, we prepared six different kinds of concrete mixtures with two types of cement and three different water-cement ratios. We have performed measurement of saturated permeability, determination of drying WRC and standard test for water penetration on each mixture.

The experimental constants for the composition of the concrete are the grain size distribution curve of the aggregates and the volumetric water content $\left(v=177 \mathrm{l} / \mathrm{m}^{3}\right)$. The experimental variables concerning to concrete composition for each mix are the quantity of cement $\left(300 \mathrm{~kg} / \mathrm{m}^{3}, 360 \mathrm{~kg} / \mathrm{m}^{3}, 420 \mathrm{~kg} / \mathrm{m}^{3}\right)$ and the quality of cement (CEM II AS 42.5 N, CEM I 42.5 NS).

The applied cements were CEM I $42.5 \mathrm{~N}-\mathrm{S}$ which is a homogeneous Portland cement with 95-100\% clinker content and CEM II A-S $42.5 \mathrm{~N}$ which is a heterogeneous Portland cement with $80-94 \%$ clinker and 6-20\% slag content. The examined mixtures are shown in Table 1.

Three specimens with size of $150 \times 150 \times 150 \mathrm{~mm}$ from each concrete mixture were prepared according to the standards for the test of watertightness. For measuring of saturated permeability and the drying water retention curve, 8 cylindrical samples having a height of $20 \mathrm{~mm}$ and a diameter of $38 \mathrm{~mm}$ were constituted.

\subsection{Standard test for water penetration}

The standard tests for water penetration were performed following the procedure described in MSZ EN 12390-8:2009. Three specimens per mixture were used for these tests. After specimen preparation a water pressure of $500 \mathrm{kPa}$ was applied on a circular part of one surface of the specimen for 72 hours. After this period the specimen was cut, and the depth of penetrations were obtained by visual inspection. [1]

Table 1 Concrete mixtures for the laboratory tests

\begin{tabular}{lccc}
\hline $\begin{array}{l}\text { Concrete } \\
\text { mixture, No. }\end{array}$ & $\begin{array}{c}\text { Quantity of } \\
\text { cement, }\left(\mathrm{kg} / \mathrm{m}^{3}\right)\end{array}$ & Quality of cement & $\begin{array}{c}\text { Water-cement } \\
\text { ratio }\end{array}$ \\
\hline$\# 1$ & 300 & CEM II A-S 42.5 N & 0.59 \\
$\# 2$ & 360 & CEM II A-S 42.5 N & 0.49 \\
$\# 3$ & 420 & CEM II A-S 42.5 N & 0.42 \\
$\# 4$ & 300 & CEM I 42.5 N-S & 0.59 \\
$\# 5$ & 360 & CEM I 42.5 N-S & 0.49 \\
$\# 6$ & 420 & CEM I 42.5 N-S & 0.42 \\
\hline
\end{tabular}


Table 2 Measured permeability coefficients

\begin{tabular}{|c|c|c|c|c|c|}
\hline \multirow{2}{*}{$\begin{array}{l}\text { Sample } \\
\text { No. }\end{array}$} & \multicolumn{4}{|c|}{ Saturated permeability coefficients, k (m/s) } & \multirow{2}{*}{$\begin{array}{l}\text { Average perme- } \\
\text { ability }(\mathrm{m} / \mathrm{s})\end{array}$} \\
\hline & $5-10 \mathrm{kPa}$ & $100 \mathrm{kPa}$ & $200 \mathrm{kPa}$ & $300 \mathrm{kPa}$ & \\
\hline 1.1 & - & $1.48 \mathrm{E}-10$ & $1.27 \mathrm{E}-10$ & - & $1.79 \mathrm{E}-10$ \\
\hline 1.2 & - & $8.48 \mathrm{E}-11$ & - & $8.48 \mathrm{E}-11$ & \\
\hline 1.3 & - & $2.27 \mathrm{E}-10$ & - & $2.82 \mathrm{E}-10$ & \\
\hline 1.4 & - & $1.27 \mathrm{E}-10$ & $3.49 \mathrm{E}-10$ & $7.91 \mathrm{E}-10$ & \\
\hline 2.1 & - & $2.05 \mathrm{E}-10$ & $1.54 \mathrm{E}-10$ & - & $4.73 \mathrm{E}-10$ \\
\hline 2.2 & - & $5.26 \mathrm{E}-10$ & - & $4.73 \mathrm{E}-10$ & \\
\hline 2.3 & - & $7.30 \mathrm{E}-10$ & - & $7.51 \mathrm{E}-10$ & \\
\hline 3.2 & - & $1.03 \mathrm{E}-10$ & $1.03 \mathrm{E}-10$ & - & $3.56 \mathrm{E}-10$ \\
\hline 3.3 & - & $8.32 \mathrm{E}-10$ & - & $4.68 \mathrm{E}-10$ & \\
\hline 3.4 & - & $3.15 \mathrm{E}-10$ & - & $3.15 \mathrm{E}-10$ & \\
\hline 4.1 & $1.26 \mathrm{E}-10$ & - & $2.11 \mathrm{E}-10$ & $5.27 \mathrm{E}-10$ & $1.96 \mathrm{E}-10$ \\
\hline 4.2 & $2.67 \mathrm{E}-10$ & - & $3.84 \mathrm{E}-10$ & $5.33 \mathrm{E}-10$ & \\
\hline 4.3 & $4.64 \mathrm{E}-11$ & $5.37 \mathrm{E}-11$ & - & $5.37 \mathrm{E}-11$ & \\
\hline 4.4 & $4.36 \mathrm{E}-11$ & $5.18 \mathrm{E}-11$ & - & $5.18 \mathrm{E}-11$ & \\
\hline 5.1 & - & $4.66 \mathrm{E}-10$ & - & $2.12 \mathrm{E}-10$ & $3.47 \mathrm{E}-10$ \\
\hline 5.2 & - & $2.12 \mathrm{E}-10$ & $1.06 \mathrm{E}-10$ & - & \\
\hline 5.3 & - & $8.38 \mathrm{E}-10$ & - & $5.24 \mathrm{E}-10$ & \\
\hline 5.4 & - & $2.09 \mathrm{E}-10$ & - & $2.09 \mathrm{E}-10$ & \\
\hline 6.1 & - & - & $1.05 \mathrm{E}-10$ & $1.05 \mathrm{E}-10$ & $1.33 \mathrm{E}-10$ \\
\hline 6.2 & - & $3.11 \mathrm{E}-10$ & - & $1.45 \mathrm{E}-10$ & \\
\hline 6.3 & - & $1.05 \mathrm{E}-10$ & - & $1.05 \mathrm{E}-10$ & \\
\hline 6.4 & - & $1.04 \mathrm{E}-10$ & - & $8.31 \mathrm{E}-11$ & \\
\hline
\end{tabular}

\subsection{Measured saturated permeability coefficients}

The permeability coefficients have been determined by constant and falling head permeability tests performed on concrete samples having a diameter of $38 \mathrm{~mm}$ and a height of $20 \mathrm{~mm}$. In total 22 soil samples have been tested, for all samples at least two tests at $100 \mathrm{kPa}, 200 \mathrm{kPa}$ or $300 \mathrm{kPa}$ head difference have been performed, some additional tests for Mixtures 4 with lower head differences have been also conducted. The determined permeability coefficient values are summarized in Table 2 .

The measured permeability coefficient values varied between $4.4 \times 10^{-11} \mathrm{~m} / \mathrm{s}$ and $8.4 \times 10^{-10} \mathrm{~m} / \mathrm{s}$; which is a quite narrow range considering the large variety of concrete types.

\subsection{Measured drying water retention curves}

The drying water retention curve of each specimen has been determined by sand/kaolin box and pressure membrane extractor. The diameter and the height of the samples were the same as used for the measurement of permeability. The tests were performed for all samples at 7 different value of matric suction. In sand/kaolin box were measured the volumetric water content at $\mathrm{pF} 0, \mathrm{pF} 0.4, \mathrm{pF} 1, \mathrm{pF} 1.5$ and $\mathrm{pF} 2.0(0.1 \mathrm{kPa}$, $0.25 \mathrm{kPa}, 1 \mathrm{kPa}, 3.2 \mathrm{kPa}, 10 \mathrm{kPa}$ ) suction values. Furthermore, in pressure membrane apparatus was determined volumetric water content of $\mathrm{pF} 3.4(251.2 \mathrm{kPa})$ suction value.

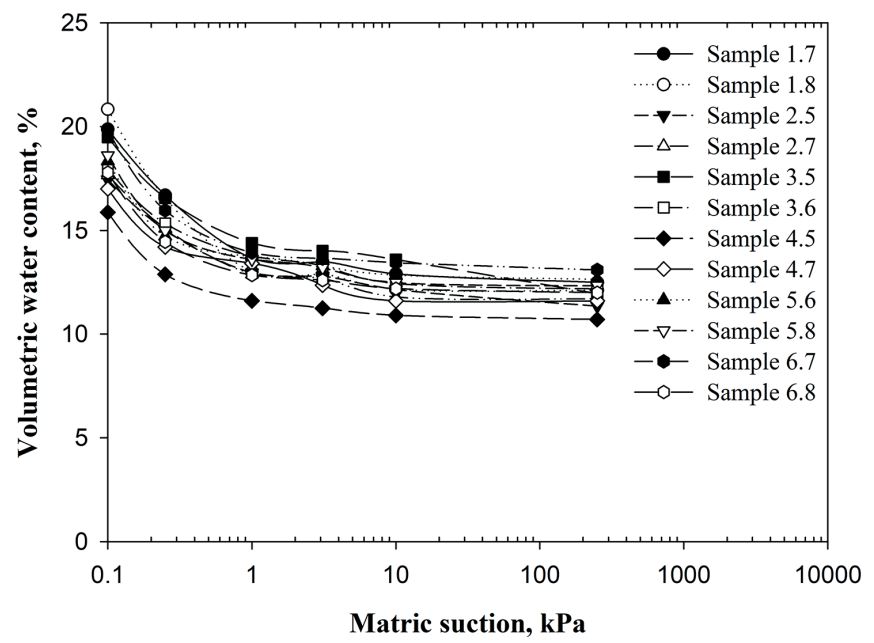

Fig. 4 Measured drying water retention curves for concrete

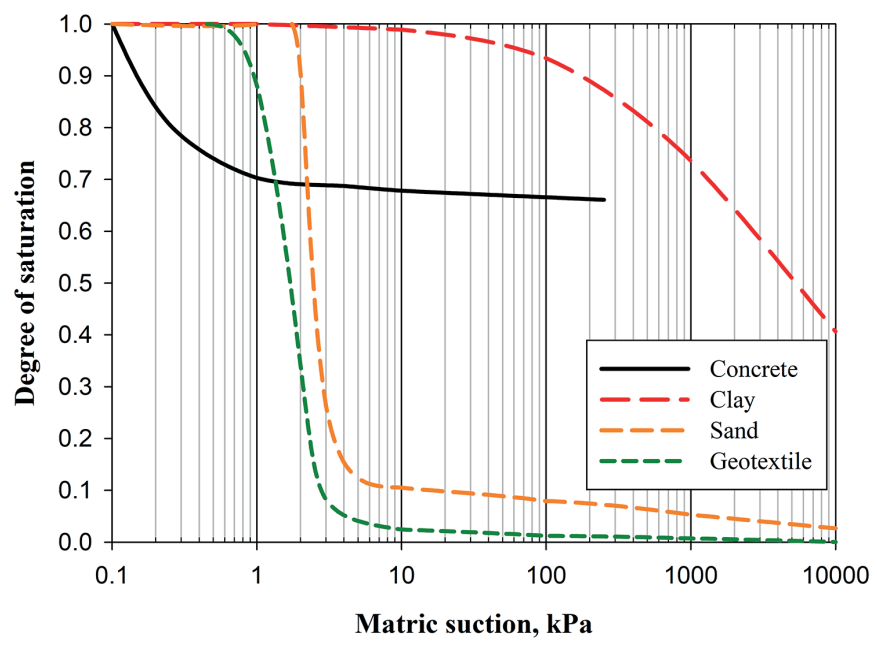

Fig. 5 Comparison of water retention curve of concrete, clay, sand and geotextile

Fig. 4 shows the measured water retention curves of concrete samples. The curves are very similar, on the first section to $1 \mathrm{kPa}$ of suction the water content significantly decrease with increasing suction, which implies that a non-negligible water loss is occurring here. On the second section of the curves the water content is nearly constant with increasing suction up to $251.2 \mathrm{kPa}$.

Fig. 5 illustrates the specific water retention curves of concrete, compared to that of clay and sand. Studies have been carried out on the determination of the water retention curve for other material used in geotechnical engineering [9]. Fig. 5 shows as well as the WRC of geotextile for further information. On this figure, the WRC is plotted using the degree of saturation instead of volumetric water content. As it was previously seen, as the suction increases, the concrete gives a large amount of water to a suction of $1 \mathrm{kPa}$ and finally converts to a nearly constant degree of saturation up to a suction of 251.2 $\mathrm{kPa}$. The phenomenon can be explained by the complex pore system of concrete. The complex pore system is made up of opened macropores and capillary pores. In low suction range the water quickly escapes from the opened macropores. Water evaporation during concrete solidification generates capillary pores where the surface tension prevents water to leave the 
structure of the concrete up to a higher suction value dependent on the surface tension. This suggests that there may be another drop in the high suction range; further measurements are needed to confirm this theory.

\section{Fitting method of measured WRC of concrete}

During the test for the water retention curve, we can only measure few points of the function because we can only define a volumetric water content value for a given suction value. Therefore, it is necessary to fit the mathematically descriptive function to the measured points for feasibility. There are several empirical functions that determine the volumetric water content for the suction value using the appropriate parameters $[5,7,12]$.

Van Genuchten [12] model is the most commonly used relationship for soils to fit the water retention curves. The model has been developed to determine the permeability function of soils. The equation shows the water content by three parameters depending on suction:

$$
\theta(\psi)=\frac{\theta_{s}}{\left[1+(a \psi)^{n}\right]^{m}}
$$

where $\theta_{s}$ is the saturated water content, and $\psi$ suction, the $a, n$ and $m$ fitting parameters.

Equation (1) is limited to the range between the air entry value and the suction value for the residual volumetric water content due to the asymptotic nature of the equation.

The model developed by Fredlund and Xing [5] is proved to be applicable for the description of the water retention curves of non-soil materials. The formula includes a correction factor that extends the suction range from residual suction to fully dry state. The natural logarithm model of Fredlund and Xing [5] is the following:

$$
\theta(\psi)=C(\psi) \cdot \frac{\theta_{s}}{\left\{\ln \left(e+\left(\psi / a_{f}\right)^{n_{f}}\right)\right\}^{m_{f}}}
$$

where $\theta(\psi)$ is the volumetric water content at the given suction value, $\psi$ is suction value, $\theta_{s}$ is the saturated volumetric water content, the $a_{f}, n_{f}$ and $m_{f}$ are fitting parameters and $C(\psi)$ is the correction factor.

The correction factor can be defined as follows:

$$
C(\psi)=1-\frac{\ln \left(1+\left(\psi / \psi_{r}\right)\right)}{\ln \left(1+\left(10^{6} / \psi_{r}\right)\right)}
$$

where $\psi_{r}$ is the value of suction to the residual volumetric water content.

Fig. 6 shows the water retention curve of sample 6.8 and its approximations by Fredlund and Xing (1994) and van Genuchten (1980) models. It seems that the more flexible Fredlund and Xing (1994) model can approximate the measured data more accurately. The van Genuchten (1980) model cannot really capture the measured water retention curves of concrete, ecause the formula is not as flexible as in the case of Fred-

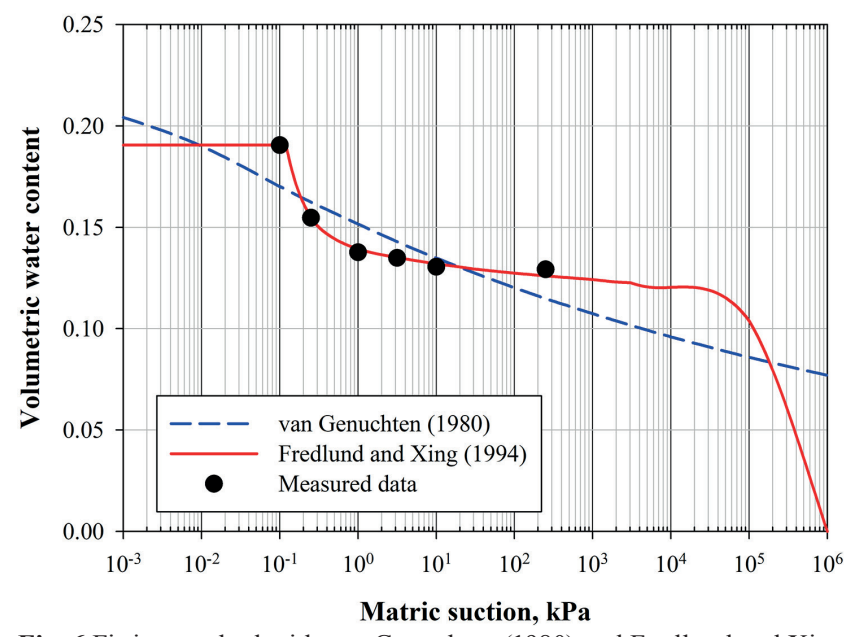

Fig. 6 Fitting method with van Genuchten (1980) and Fredlund and Xing (1994) model

lund and Xing (1994). Equation (2) was found to be capable of describing water retention characteristics of other materials (eg. geotextile) [9], and now it is found to be applicable to fit the water retention curve of concrete.

\section{Estimation of the wetting water retention curve}

The drying water retention curve is generally the first curve determined for a material, as reaching the equilibrium on the drying side is quicker than on the wetting side. The wetting curve is usually estimated by assuming an appropriate lateral shift for the drying curve. It can be also assumed that the drying and wetting curves are parallel to one another in the inflection point portion of the curves. The mentioned assumptions appear to be commonly applied in geotechnical engineering. [3,10]

Thus, the wetting SWRC is estimated by a horizontal translation to the left in the semi-logarithmic space. The $a$ fitting parameter of the SWRC equations generally control the lateral shift of the drying and wetting SWRCs. The $n$ and $m$ fitting parameters are kept constant for all curves. The percent shift of the SWRC boundary curves, $\xi$ is defined on a logarithmic scale. Therefore, a $100 \%$ shift corresponds to one log scale of change. This means that the $a$ fitting parameter will have to change by one order of magnitude. [3]

The percent lateral shift of the SWRC boundary curves, $\xi$ can be written as follows [3]:

$$
\xi=100\left[\log \left(\psi_{a d}\right)-\log \left(\psi_{a w}\right)\right]
$$

where $\psi_{a d}$ is the suction at any point along the drying SWRC, and $\psi_{a w}$ is the suction at any corresponding water content on the wetting SWRC. With the former formula, the lateral shift can be determined from any point at the curve.

The Eq. (4) representing the lateral shift of the SWRC can be rearranged such that the suction on a congruent SWRC can be computed from the drying curve. Then, Eq. (4) can be written as follows [3]:

$$
\psi_{w}=10^{\left(\log \psi_{d}-\xi \xi / 100\right)}
$$


Pham [10] analyzed the lateral shift between the drying and wetting SWRCs for published data from various researchers. It was found that the largest shift between the drying and wetting curves existed for clay soils (50-100), and the smallest shift occurred for uniform sand soils (15-35).

Fig.7 shows the measured drying and the estimated water retention curve of concrete sample. The lateral shift values for concrete mixtures have been determined during the finite element back-analysis of the performed standard test for watertightness.

\section{Estimated unsaturated permeability function}

The estimation technique for describing the water permeability functions can be subdivided into different categories. There are groups of proposed estimation models that are based on statistical assumptions regarding the pore distributions. These models are developed based on the interpretation of the SWRC and are usually categorized as either macroscopic approaches or microscopic approaches; the macroscopic models provide a closed-form analytical equation for the unsaturated permeability function. [3, 6, 7, 12, 13]

Van Genuchten [12] and Fredlund et al. [6] models are the most commonly used equations for soils to calculate the unsaturated permeability function. Van Genuchten [12] model is expressed as follows:

$$
k_{r}=\frac{\left\{1-(a \psi)^{n-1}\left[1+(a \psi)^{n}\right]^{-m}\right\}^{2}}{\left[1+(a \psi)^{n}\right]^{m / 2}}
$$

Fredlund et al. [6] used the Fredlund and Xing (1994) SWRC equation to compute a water permeability function. The procedure involved numerical integration along the SWRC. Independent permeability functions can be computed for the drying and wetting SWRC. It is assumed that the volume change of the soil structure is negligible when soil suction is changed.

Fredlund et al. [6] equation was written in the following form:

$$
k_{r}(\psi)=\frac{\int_{\ln (\psi)}^{b} \frac{\theta\left(e^{y}\right)-\theta(\psi)}{e^{y}} \theta^{\prime}\left(e^{y}\right) d y}{\int_{\ln \left(\psi_{\text {aev }}\right)}^{b} \frac{\theta\left(e^{y}\right)-\theta_{s}}{e^{y}} \theta^{\prime}\left(e^{y}\right) d y}
$$

where $b$ the upper limit of integration [i.e., $\ln \left(10^{6}\right)$ ], y dummy variable of integration representing the logarithm of suction, $\theta^{\prime}$ derivative of the SWRC equation, $e^{y}$ natural number raised to the dummy variable power.

Fig. 8 shows the relationship between suction and permeability, which demonstrates that the increasing suction causes a significant reduction in permeability by more order of magnitudes. The figure also indicates that van Genuchten (1980) model provide unrealistically low values for $k / k_{\text {sat }}$ ratio. Fig. 9 shows the drying and the wetting permeability functions estimated by Fredlund et. al. (1994) model.

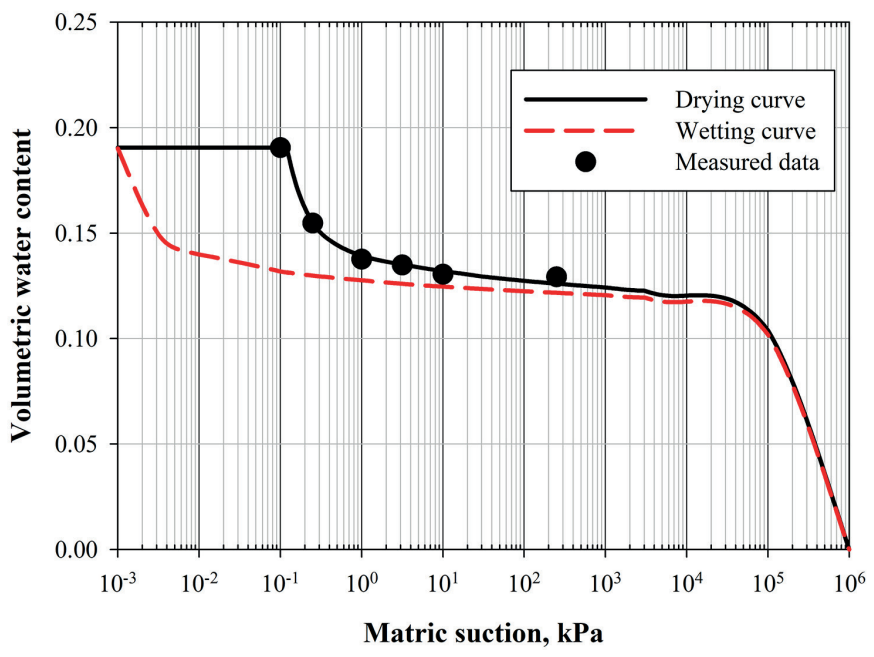

Fig. 7 Estimation of wetting water retention curve for concrete using lateral shift

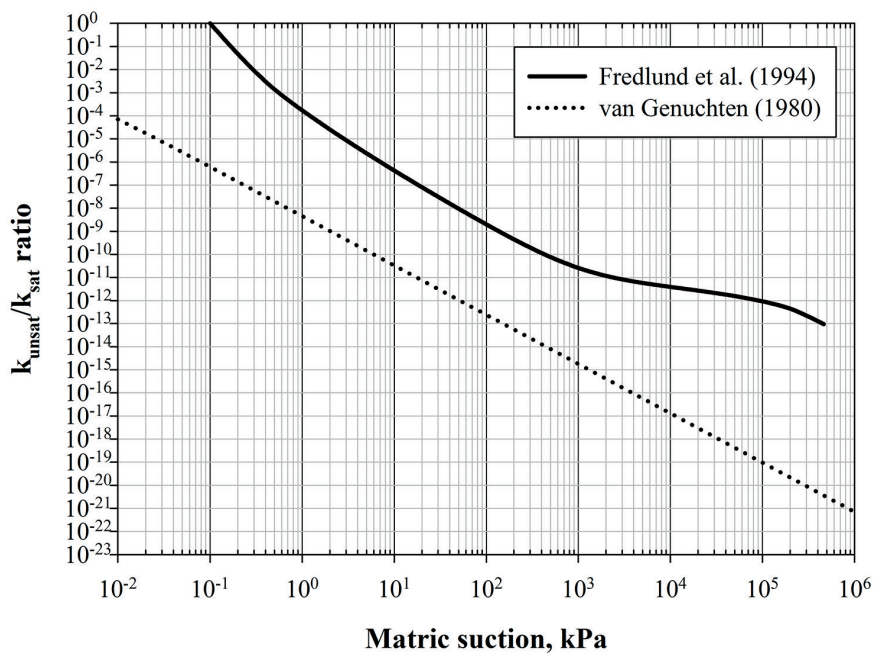

Fig. 8 Estimated permeability function for concrete using van Genuchten (1980) and Fredlund et al. (1994) model

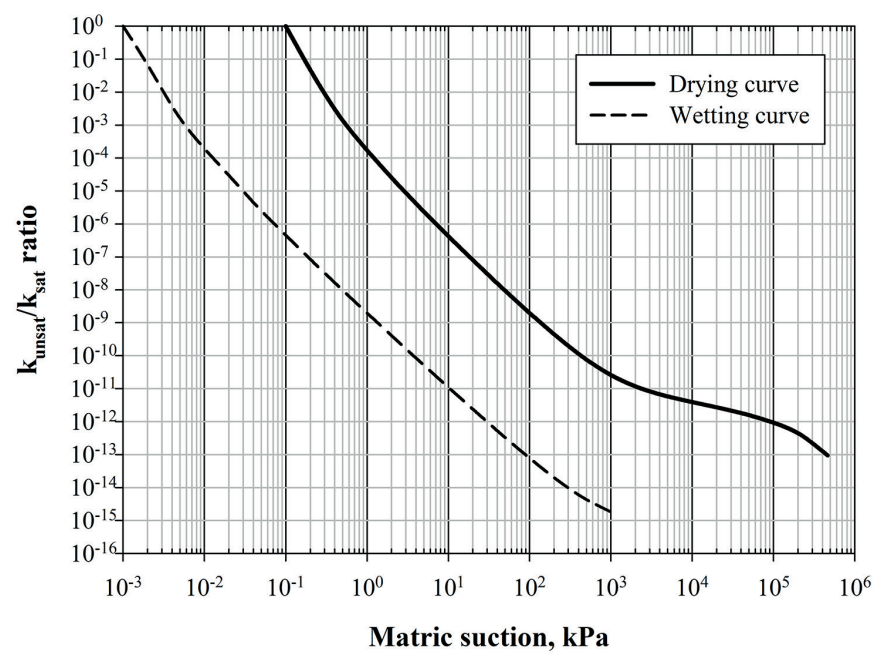

Fig. 9 Permeability function for concrete during wetting and drying process

\section{Back-analysis of standard test for water penetration 6.1 Geometry}

The back-analysis was performed using Midas GTS finite element software. Previously, we have shown that the standard test for water penetration was carried out on concrete samples 
size of $150 \times 150 \times 150 \mathrm{~mm}$. During the modeling, we simplified the geometry to accelerate the calculation by taking advantage of symmetry, so we modeled only a quarter of the sample (Fig. 10).

The depth of water penetration was detected on a circular surface with diameter of $75 \mathrm{~mm}$ at 5 bar water pressure. During the mesh generation, triangular prismatic finite elements were used. Refining of the coarseness was determined by the location of the water penetration; the elements were refined on the vertical sides in the upper part of the model and on the horizontal plane on the quarter circle where water pressure is applied. The finite element mesh was validated by a calculation using finer mesh.

\subsection{Material properties}

Finite element seepage analysis requires the following material properties: saturated permeability coefficients, initial volumetric water content and concrete functions (WRC, permeability function). These parameters shall be adjusted so that the numerical model provides results similar to the measured ones.

During the modelling, the saturated permeability values given in the last column of Table 2 were used and isotropic seepage behavior was assumed.

The average value of volumetric water contents measured on the concrete specimens were used as initial water contents during the back analyses. Table 3 shows the average value of volumetric water content for each concrete mixture.

For back-analysis, the concrete functions of adsorption process can be estimated using the drying water retention curve. The only variable was the lateral shift, which only changes the $a$ fitting parameter, the $n$ and $m$ parameters were kept constant as previously mentioned.

\subsection{Boundary conditions}

Water pressure of 5 bar was specified on the quarter circle in the model as boundary condition, and closed seepage boundaries were assigned to the symmetry axes. The seepage in concrete was computed as a transient flow, for which time stairs are also required. The time interval of standard test for watertightness is $72 \pm 2$ hours, so a time step has already been given.

The other time steps are determined thus that the test process can be observed if an anomaly occur. As the result, the time steps are 1 hour, 10 hours, 24 hours, and 72 hours (Fig. 11).

Table 3 Initial volumetric water content

\begin{tabular}{lc}
\hline Concrete mixture No. & Initial volumetric water content (\%) \\
\hline$\# 1$ & 4.7 \\
$\# 2$ & 5.4 \\
$\# 3$ & 5.2 \\
$\# 4$ & 4.8 \\
$\# 5$ & 5.5 \\
$\# 6$ & 5.3 \\
\hline
\end{tabular}

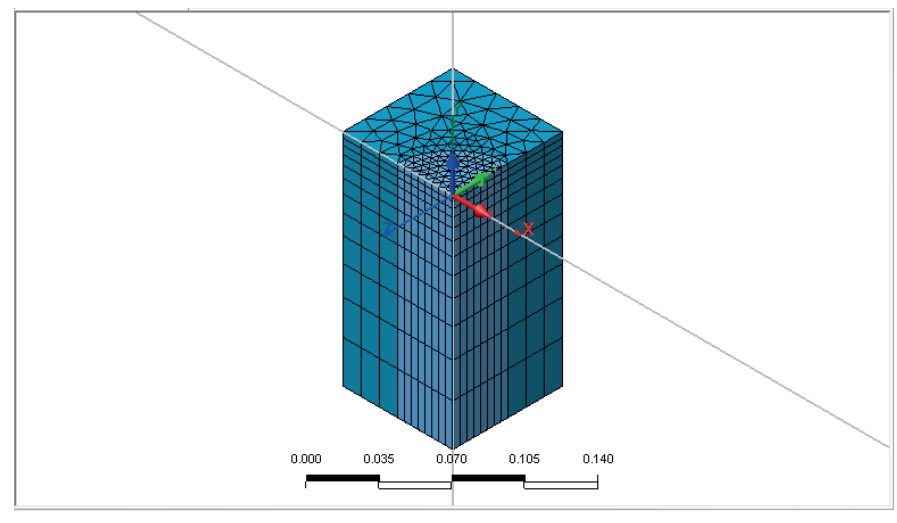

Fig. 10 Model geometry of concrete specimen
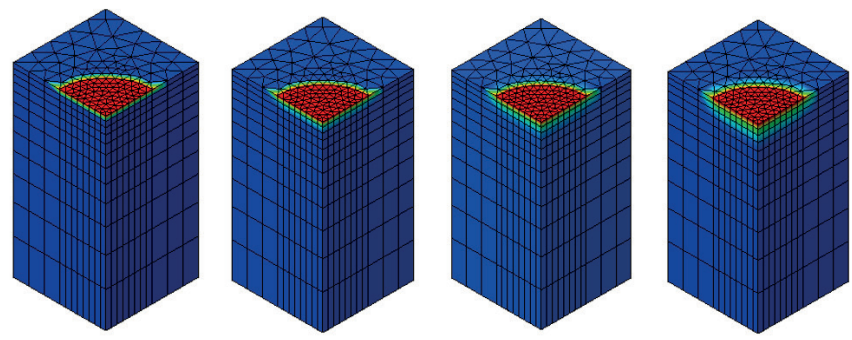

Fig. 11 Pore pressure in concrete specimen during standard test for watertightness

\subsection{Results of the back-analysis}

We have previously mentioned that the lateral shift is the only variable parameter of the concrete functions, and the purpose of the back analyses was to determine the lateral shift values for each concrete mixture that leads to the best approximation of the experienced behavior.

The calculation was carried out on models of six different concrete mixtures. The depth of water penetration (i.e. the boundary of the saturated/unsaturated zones) was determined based on the computed pore water pressure values: the water pressure value of $0.1 \mathrm{kPa}$ was selected to define this boundary, because numerical uncertainties were observed with lower water pressure values.

Fig. 12 shows the pore water pressure values at the vertical axis going through the center of the circle in logarithmic scale. In each case there is a logarithmic relationship between water pressure and depth below the specimen's surface, thus is the computed pore water pressure tends asymptotically to zero. In figure 11, the intersection of the two axis is set to $0.1 \mathrm{kPa}$ so that the water penetration depths on the models can be compared to each other. The maximum depth of water penetration was determined on the vertical axis of concrete samples (Fig. 13).

The water penetration depth values were compared in the middle vertical axis of each specimen due to outlined above. This finding is appropriate approximation for certain concrete mixtures but in case of watertight structures the maximum water penetration depth is not necessarily observed in the middle section of specimen. This study deals with the comparison of the maximum water penetration depths determined in the middle vertical axis. 


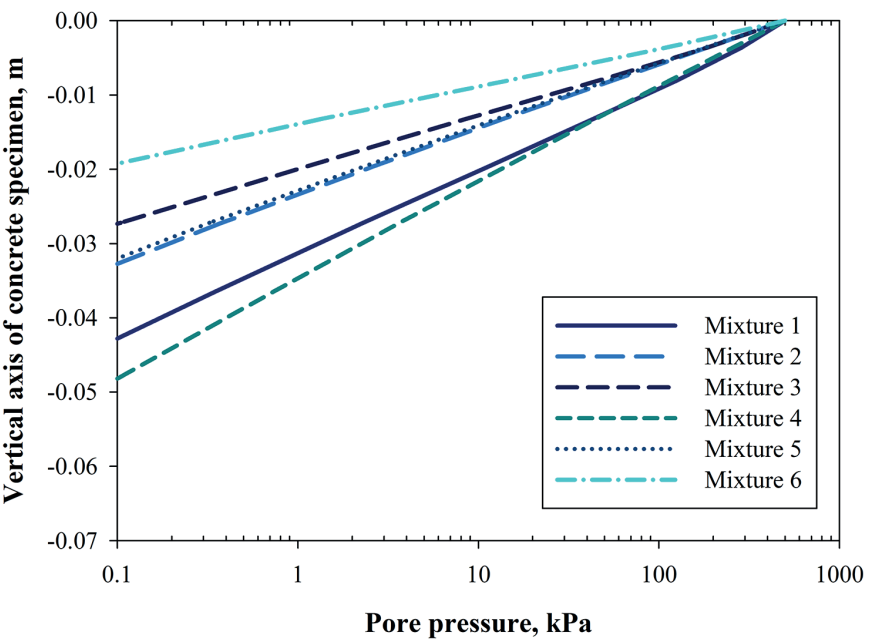

Fig. 12 Pore pressure inside the concrete specimen
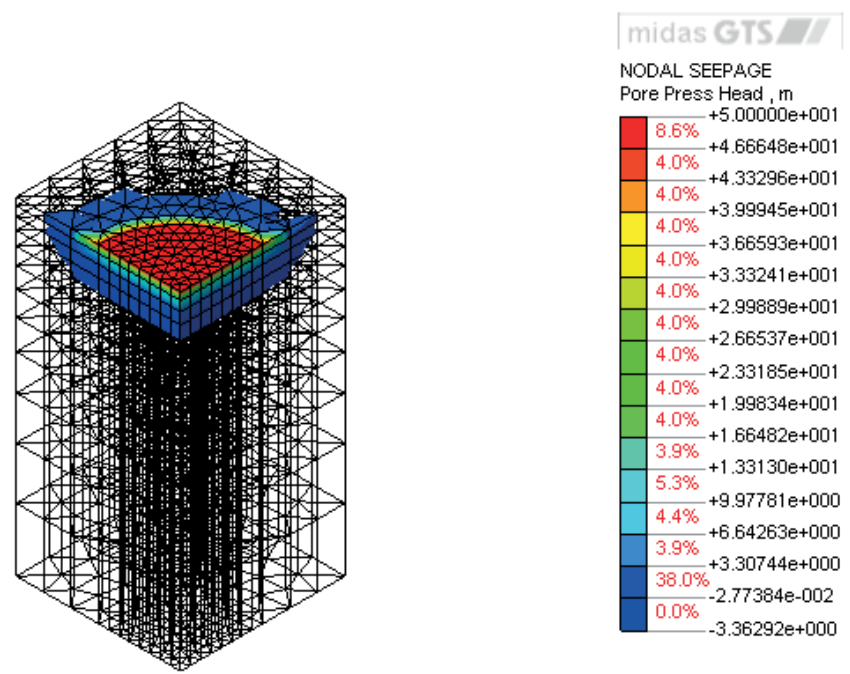

Fig. 13 Shape of the water penetration in back-analysis for Mixture 6

The lateral shift values were estimated by iteration: its value have been being changed until the water penetration given by the test and by the finite element model are identical. The lateral shift values determined by this iteration are shown in Table 4. It can be observed that in the case of concrete the lateral shift values are larger than that of soils, thus the hysteresis on the water retention curves of concrete may also be greater. The results also show that the range of lateral shift values are higher using CEM II AS $42.5 \mathrm{~N}$ (145-215) than that of CEM I $42.5 \mathrm{~N}-\mathrm{S}$ (130-175) when using the same w/c ratio.

Fig. 14 and 15 show the test results and the back-analysis results of first concrete mixtures. The figures show that the water penetration shape of the model approaches the water tightness test, but significant differences can be observed at the edge of the specimen. This can be caused by either heterogeneity or anisotropy of the specimen.

\section{Conclusions}

During our experiments, the seepage in concrete were studied using theories and measurement methods of unsaturated soil mechanics. The concrete mixtures tested were prepared using two types of cement grades (CEM II AS 42.5 N, CEM I 42.5 NS)
Table 4 Lateral shift value for each concrete mixture

\begin{tabular}{lc}
\hline Concrete mixture No. & Lateral shift $(\%)$ \\
\hline$\# 1$ & 145 \\
$\# 2$ & 215 \\
$\# 3$ & 200 \\
$\# 4$ & 130 \\
$\# 5$ & 160 \\
$\# 6$ & 175 \\
\hline
\end{tabular}

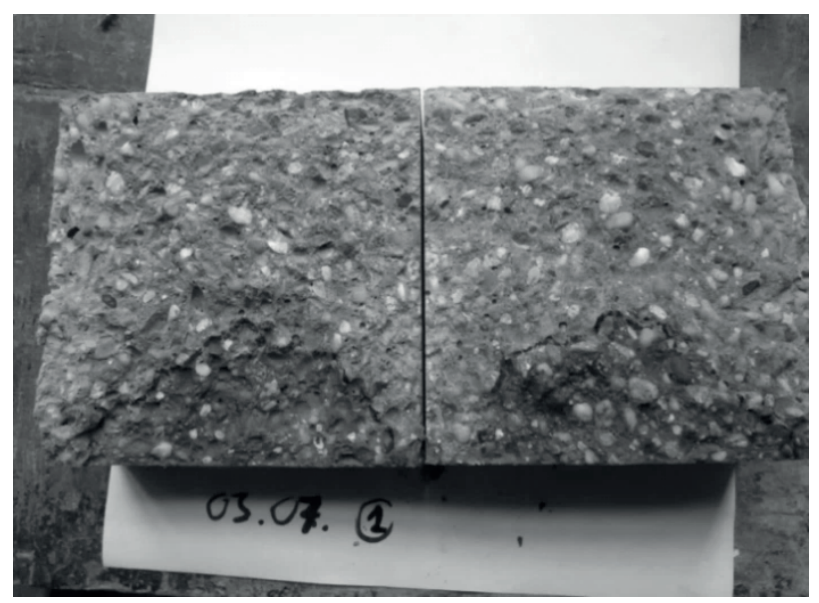

Fig. 14 Water penetration shape of the concrete specimen for Mixture 1
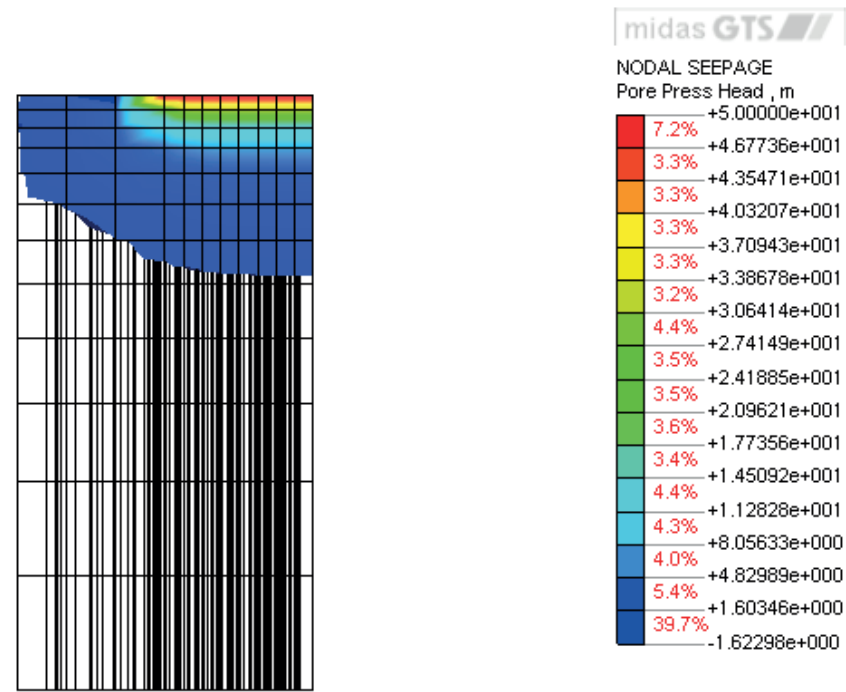

Fig. 15 Shape of the water penetration in back-analysis for Mixture 1

and three different water-cement ratios $(0.59 ; 0.49 ; 0.42)$. In summary six different concrete mixtures have been tested for water retention, saturated permeability and watertightness.

A relatively narrow range of permeability $\left(4.36 \times 10^{-11}\right.$ to $8.38 \times 10^{-10} \mathrm{~m} / \mathrm{s}$ ) values were obtained for the various concrete types tested. The water retention curve of concrete is significantly different than that of soils. At low suction range, the water content of concrete decreases, but afterwards the water content is almost constant up to a suction value of $251.2 \mathrm{kPa}$. In case of concrete Fredlund and Xing (1994) and Fredlund et al. (1994) model used to determine describe the water retention curve and the permeability function provide a more accurate 
approximation compared to van Genuchten (1980). Due to the permebaility function of concrete the permeability coefficient decreases significant with decreasing water content.

The measured and calculated data enable the numerical back-analysis of the standard test for watertightness. For the determination of the required wetting water retention curve the lateral shift was used. The back-analysis was performed using Midas GTS finite element software.

The lateral shift for each concrete specimen were modified so that the penetration depth in the numerical analyses equal the measured ones.

It has been found that the value of lateral shift in concrete was higher than in the case of soils. For concrete prepared with CEM II AS 42.5 N the values were between 145 and 215, for concrete made with CEM I 42.5 NS the values were 130 to 175. The maximum depth of water penetration on the models approximate the values measured during standard test for watertightness.

The theories of soil mechanics are suitable for analyzing water flow in concrete, but further clarifications are still needed.

\section{References}

[1] Balázs, L. Gy., Kausay, T. "Vízzáró beton és vizsgálata" (in Hungarian), (Watertight concrete and its testing possibilities), Vasbetonépités, 12(2), pp. 47-57, 2010.

[2] Fredlund, D. G., Rahardjo, H., Fredlund, M. D. "Unsaturated Soil Mechanics in Engineering Practice", John Wiley \& Sons, New Jersey, USA, 2012.

https://doi.org/10.1002/9781118280492

[3] Fredlund, D. G., Sheng, D., Zhao, J. "Estimation of soil suction from the soil-water characteristic curve". Canadian Geotechnical Journal, 48(2), pp. 186-198, 2011. https://doi.org/10.1139/T10-060

[4] Fredlund, D. G. "The 1999 R.M. Hardy Lecture: The implementation of unsaturated soil mechanics into geotechnical engineering". Canadian Geotechnical Journal, 37(5), pp. 963-986, 2000. https://doi.org/10.1139/t00-026

[5] Fredlund, D. G., Xing, A. "Equations for the soil-water characteristic curve". Canadian Geotechnical Journal, 31(4), pp. 521-532, 1994. https://doi.org/10.1139/t94-061

[6] Fredlund, D. G., Xing, A., Huang, S. "Predicting the permeability function for unsaturated soils using the soil-water characteristic curve". Canadian Geotechnical Journal, 31(4), pp. 533-546, 1994.

https://doi.org/10.1139/t94-062

[7] Mualem, Y. "A new model for predicting the hydraulic conductivity of unsaturated porous media". Water Resources Research, 12(3), pp. 513522, 1976 . https://doi.org/10.1029/WR012i003p00513

[8] Ng, C. W. W., Menzies, B. "Advanced Unsaturated Soil Mechanics and Engineering", Taylor and Francis, New York, USA, 2007.

[9] Park, K. D., Fleming, I. R. "Evaluation of a geosynthetic capillary barrier". Geotextiles and Geomembranes, 24(1), pp. 64-71, 2006. https://doi.org/10.1016/j.geotexmem.2005.06.001

[10] Pham, H. Q., Fredlund, D. G., Barbour, S. L. "Estimation of the hysteretic soil-water characteristic curves from the boundary drying curve". In: Proceedings of the 56th Canadian Geotechnical Conference, Sep. 28-Oct. 1, 2003, Winnipeg, Canada, 2003, pp. 115-121.
[11] Taylor, D. W. "Fundamentals of Soil Mechanics", John Wiley \& Sons, New York, USA, 1948.

[12] van Genuchten, M. T. "A Closed-form Equation for Prediccting Hydraulic Conductivity of Unsaturated Soils". Soil Science Society of America Journal, 44(5), pp. 892-898, 1980. https://doi.org/10.2136/sssaj1980.03615995004400050002x

[13] Zhai, Q., Rahardjo, H. "Estimation of permeability function from the soil-water characteristic curve". Engineering Geology, 199, pp. 148-156, 2015.

https://doi.org/10.1016/j.enggeo.2015.11.001

[14] Hegyi, P., Dunai, L. "Experimental Investigation of Thin-walled Columnend Joints Encased in Ultra-lightweight Concrete". Periodica Polytechnica Civil Engineering, 61(4), pp. 951-957, 2017. https://doi.org/10.3311/PPci.10041

[15] Lublóy, É. "The Influence of Concrete Strength on the Effect of Synthetic Fibres on Fire Resistance". Periodica Polytechnica Civil Engineering, 62(1), pp. 136-142, 2018. https://doi.org/10.3311/PPci.10775

[16] Török, Á., Vásárhelyi, B. "The influence of fabric and water content on selected rock mechanical parameters of travertine, examples from Hungary". Engineering Geology, 115(3-4) pp. 237-245, 2010. https://doi.org/10.1016/j.enggeo.2010.01.005 